\title{
EFFECT OF MOUTHPIECE LENGTH AND POSITION ON THE DISCHARGE COEFFICIENT
}

\author{
Sayed E. A. Mahgoub \\ Hydraulics Research Institute, \\ The National Water Research Center
}

\begin{abstract}
This research investigates experimentally the different lengths, positions and direction of mouthpieces to determine the value of the corresponding discharge coefficient $\left(C_{d}\right)$ in order to specify the orifice characteristics that can be properly implemented in the field of irrigation. The experiments were carried out in the Hydraulic Research Institute in a two sided glass flume $(40 \mathrm{~m}$ long, $0.4 \mathrm{~m}$ wide and $0.6 \mathrm{~m}$ deep). 126 runs were executed during which the length and position of the mouthpiece were varied. The tested lengths, with respect to the orifice diameter, were $0.5 \mathrm{~d}$, $1 \mathrm{~d}, 1.5 \mathrm{~d}, 2 \mathrm{~d}, 3 \mathrm{~d}, 4 \mathrm{~d}$ and $5 \mathrm{~d}$, while the tested positions of mouthpieces were fitted either internally (opposite to the flow direction) or externally (along the flow direction). Supplementary tests (36 tests) were carried out for determining the discharge coefficient of the orifice (without mouthpieces) to act as a reference to the results using mouthpieces. The discharge was varied from 5 to $13 \mathrm{l} / \mathrm{s}$ with increment of $1 \mathrm{l} / \mathrm{s}$. Measurements were carried out using point gauges, ultrasonic flow-meter, current meters and a digital camera to monitor the flow inside and outside the tested mouthpieces.

The results were analyzed and represented. The results revealed that increasing the throat length results in decreasing the loss coefficient to a certain limit after which " $\mathrm{C}_{\mathrm{d}}$ " becomes constant. Also, the results proved that the discharge coefficient in the case of an internal mouthpiece is less than that of the case of an external mouthpiece as the separation increases. It was also found that lowering the mouthipiece under the free surface causes the increase in the head $(H)$ which produces more losses.

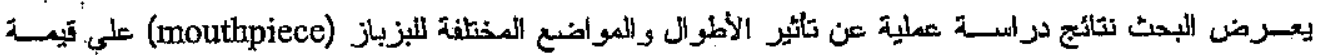

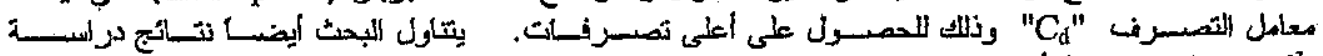

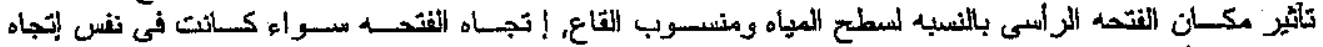

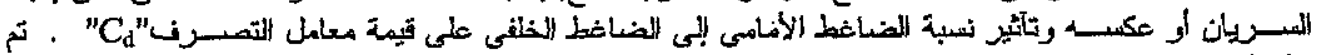

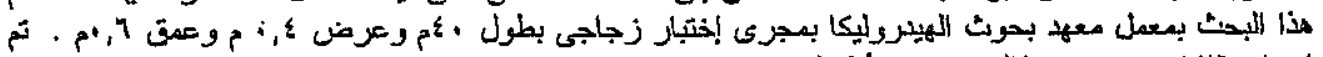

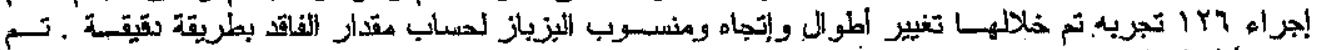

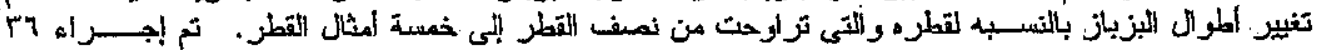

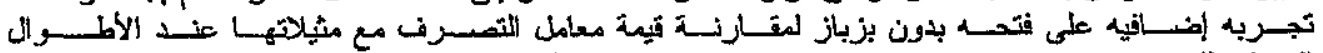

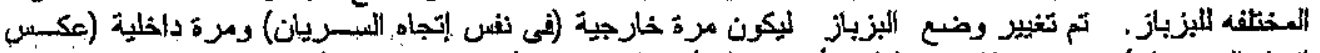

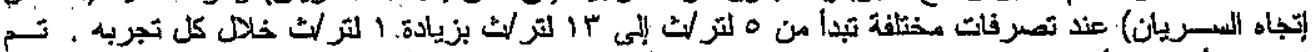

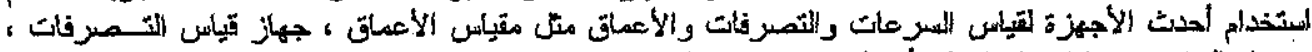

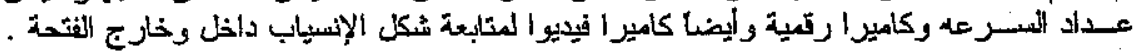

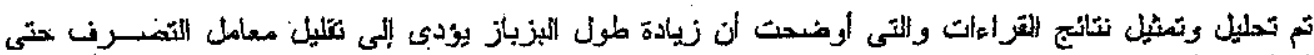

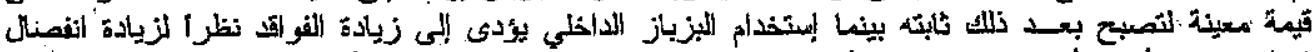

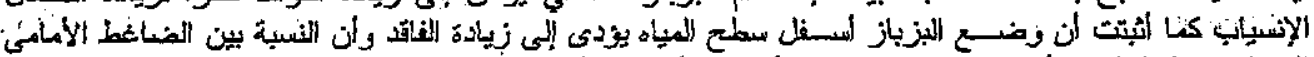

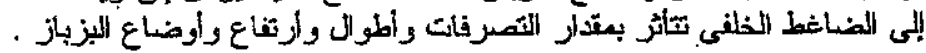

Keywords: Mouthpiece, Discharge Coefficient, Physical Model, Calibration, Separation, Losses. 


\section{INTROUDUCTJON}

Mouthpieces have many applications in irrigation and drainage systems in Egypt. Among these applications are irrigation sprinklers and pressurized irrigation and some drainage systerns. In most of the cases the system faces one main problem which is the deficiency of supplying the required designed discharge. This is due to the fact that the coefficient of discharge " $C_{d}$ " is somehow small. This coefficient is defined as the ratio between the actual discharge and the theoretical discharge which is expressed as follows:

$$
C_{d}=\frac{Q_{a t t}}{Q_{d t}}=\frac{Q_{a c t}}{A_{0} \sqrt{2 g H}}
$$

Where:

$\begin{array}{lll}\mathbf{C}_{\mathbf{d}} & \text { discharge coefiricient } & (-) \\ \mathbf{Q}_{\text {act }} & \text { actual discharge } & \left(\mathrm{m}^{3} / \mathrm{s}\right) \\ \mathbf{Q}_{\text {th }} & \text { theoretical discharge } & \left(\mathrm{m}^{3} / \mathrm{s}\right) \\ \mathbf{A}_{\mathbf{0}} & \text { area of mouthpiece }\left(\pi \mathrm{d}^{2} / 4\right) & \left(\mathrm{m}^{2}\right) \\ \mathbf{G} & \text { acceleration due to gravity } & \left(\mathrm{m} / \mathrm{s}^{2}\right) \\ \mathbf{H} & \begin{array}{l}\text { distance from mouthpiece center } \\ \end{array} & (\mathrm{m}) \\ \text { D to water surface } & \text { mouthpiece diameter } & (\mathrm{m})\end{array}$

In order to enhance the efficiency of any hydraulic system, this coefficient is desired to be close to one "l". That means it is requircd to make the actual discharge " $Q_{a a t}$ " very close to the value of the theoretical discharge " $\mathrm{Q}_{\mathrm{th}}$ ".

Many researches were carried out worldwide to investigate the discharge coefficient of the orifice and mouthpiese. These researches focused on evaluating the discharge coefficient of the mouthpiece shapes and cross sections. Most of these researches just conducled experiments on mouthpiece lengths from 2 to 3 the mouthpiece diameter. Moreover, they did not take into consideration two important factors; the first is the effect of position level with respect to the water free surface and the second is the mouthpiece direction whether it was along the flow direction or opposite to it. This current research involved also the effect of the mouthpiece lengths on the ratio of upstream head to the downstream head (HU/S /HD/S). The length was taken as a ratio with the diameter and also most output results were taken as a ratio (dimensionless) to facilitate applying these results for any different diameter or length.

This research was thus initiated to investigate the effect of various factors affecting the discharged quantities from mouthpieces in order to specify the orifice characteristics that can be properly implemented in the fielt of irrigation. Different mouthpieces were tested varying their lengths, directions, and position from the water surface. 126 runs were executed during which the length and position of the mouthpiece were varied. The tested lengths, with respect to the orifice diameter, were $0.5 \mathrm{~d}, 1 \mathrm{~d}, 1.5 \mathrm{~d}, 2 \mathrm{~d}, 3 \mathrm{~d}, 4 \mathrm{~d}$ and $5 \mathrm{~d}$, while the tested positions of the mouthpieces were fitting them either internally (opposite to the flow direction) or externally (along the flow direction). The discharge was varied from 5 to $13 \mathrm{l} / \mathrm{s}$ with an increment of $1 \mathrm{l} / \mathrm{s}$.

The investigation phases are presented in this paper under the following topics:

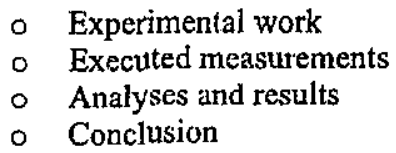

\section{EXPERIMENTAL WORK}

As a preparation to the experimental work, a testing flume in the Hydraulic Research Institute (HRI) was prepared to calibrate the measuring devices (flowmeters, current-meters, point gauges and the water pump). The preparation was also to adjust the flume slope, water depth, and flow velocity at the downstrearm.

\section{2-a. Description of the Flume}

The flume, used for the present investigation, has a rectangular cross section with total length $40.0 \mathrm{~m}, 0.6$ $\mathrm{m}$ height, and $0.4 \mathrm{~m}$ width. It has glass sheets of $1.10 \mathrm{~m} \times 0.6 \mathrm{~m}$, and $6 \mathrm{~mm}$ thickness, photos (1) to (7). The flume is placed over a concrete base $0.8 \mathrm{~m}$ high. A rectangular sluice gate is fixed at $13.5 \mathrm{~m}$ apart of the end of the entrance channel. This sluice gate can be manually operated up and down to pass different discharges at different gate operings. A movable tail gate is located at the end of the flume so as to control the tail water depth of the flume.

A plate of wood is placed at a distance of $7.0 \mathrm{~m}$ away from the inlet of the flume with the following dimensions $(0.6 \mathrm{mn} 0.4 \mathrm{~m} \times 0.01 \mathrm{~m})$. An orifice of 10 $\mathrm{cm}$ diameter in the plate was made at a height of 20 $\mathrm{cm}$ above the bed.

An exact description to the flume parts, Fig. (1) and photo (1), is given as follows:

- The Flume Inlet consists of masonry to receive the delivered water from the centrifugal pump through a pipe line that dissipates the energy of the flow to enter the model to avoid any disturbance of flow in the flume, Photo (2).

- Deceleration plate: the water passes through a deceleration movable plate $(1.0 \mathrm{~m} \times 0.33 \mathrm{~m})$ that makes the flow to be steady without any disturbances.

- Rectangular Sluice Gate: It is used for controlling the water, Photo (3).

- Tallgate $(0.4 \times 0.4)$ i it was installed at the downstream end of the flume to control the 
Sayed E. A. Mahgoub, "Effect of Mouthpiece Length and Position on The Discharge Coefficient"

downstream tail water depth and to control water.

o. The Flume Outlet; The flume outlet consists of a basin that starts directly at its end followed by a tail control gate to adjust the water levels in the model, Phöto (4).

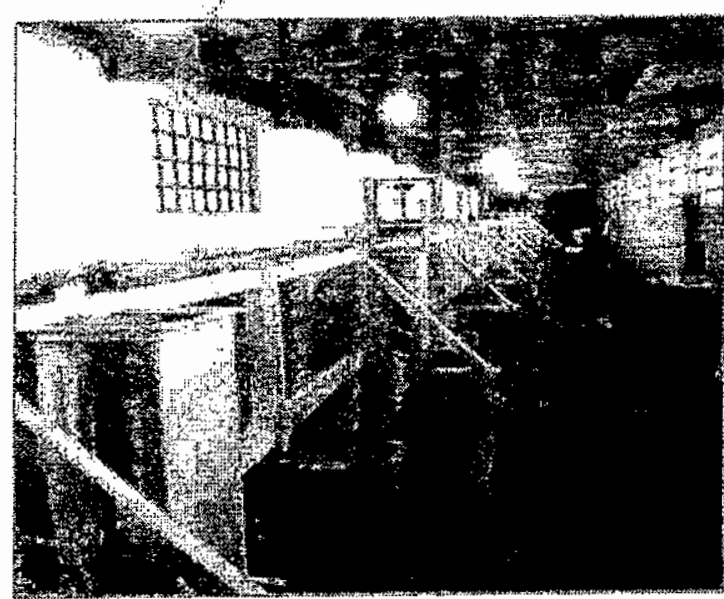

Photo (1). General Photo of the Flume

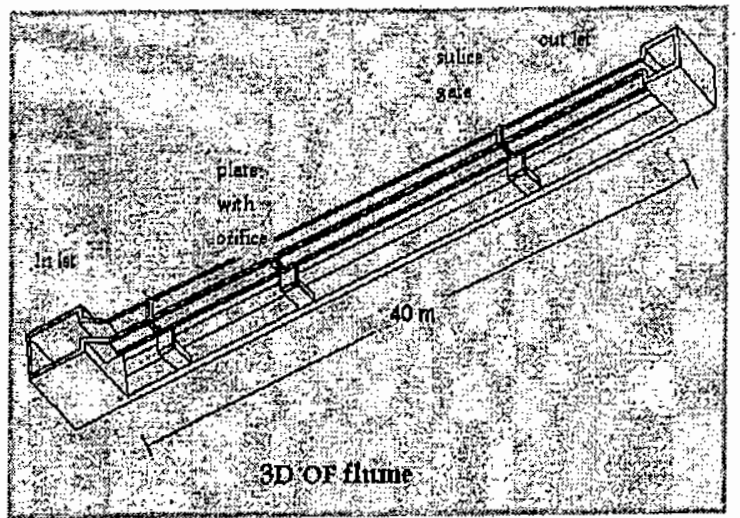

Figure 1. Cross-Section of the Flume

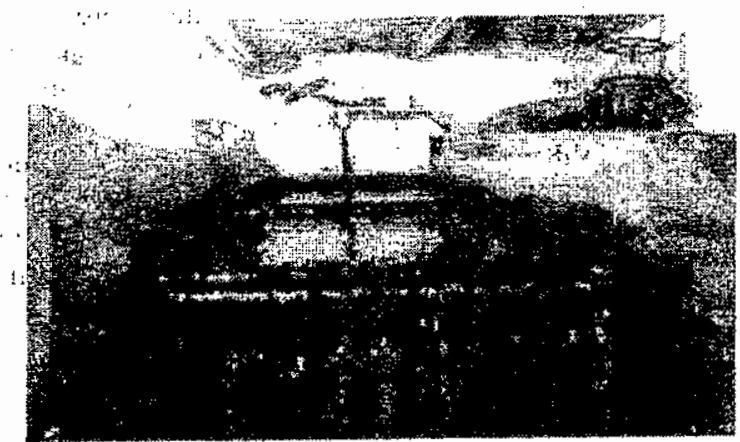

Photo (2) Flume Inlet

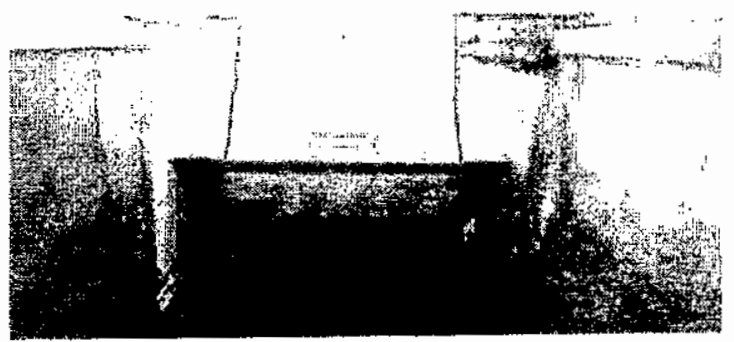

Photo (3) Control Gate

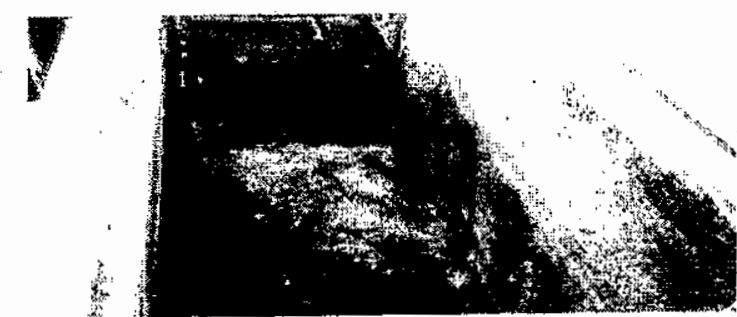

Photo (4) Flume Outlet

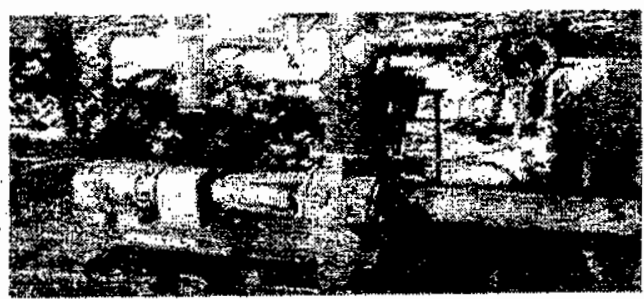

Photo (5) Feeding Water Pump

\section{2-C. Experiment Procedure}

During each run, the discharge was adjusted and determined using an ultrasonic flow meter. The upstream head $\mathrm{H}_{l}$ is firstly adjusted, then the downstream head $\mathrm{H}$ is adjusted. The length of mouthpiece is changed as a function of the diameter $L=f(d)$, Figs. (2) and (3). The water velocity is measured using a current meter and is compared to \%. the calculated values. The Froude number $F_{r}$ and $C_{d}$ are calculated. This was achieved 126 times to every mouthpiece length, discharge, water level and mouthpiece direction, Photos (6) and (7).
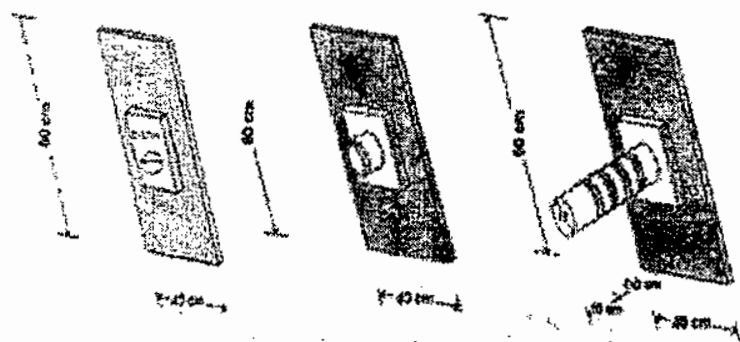

Figure 2. Cross-Sections of Different Mouthpiece Lengths 


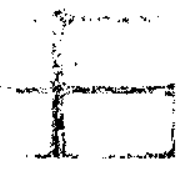

$$
L=t
$$
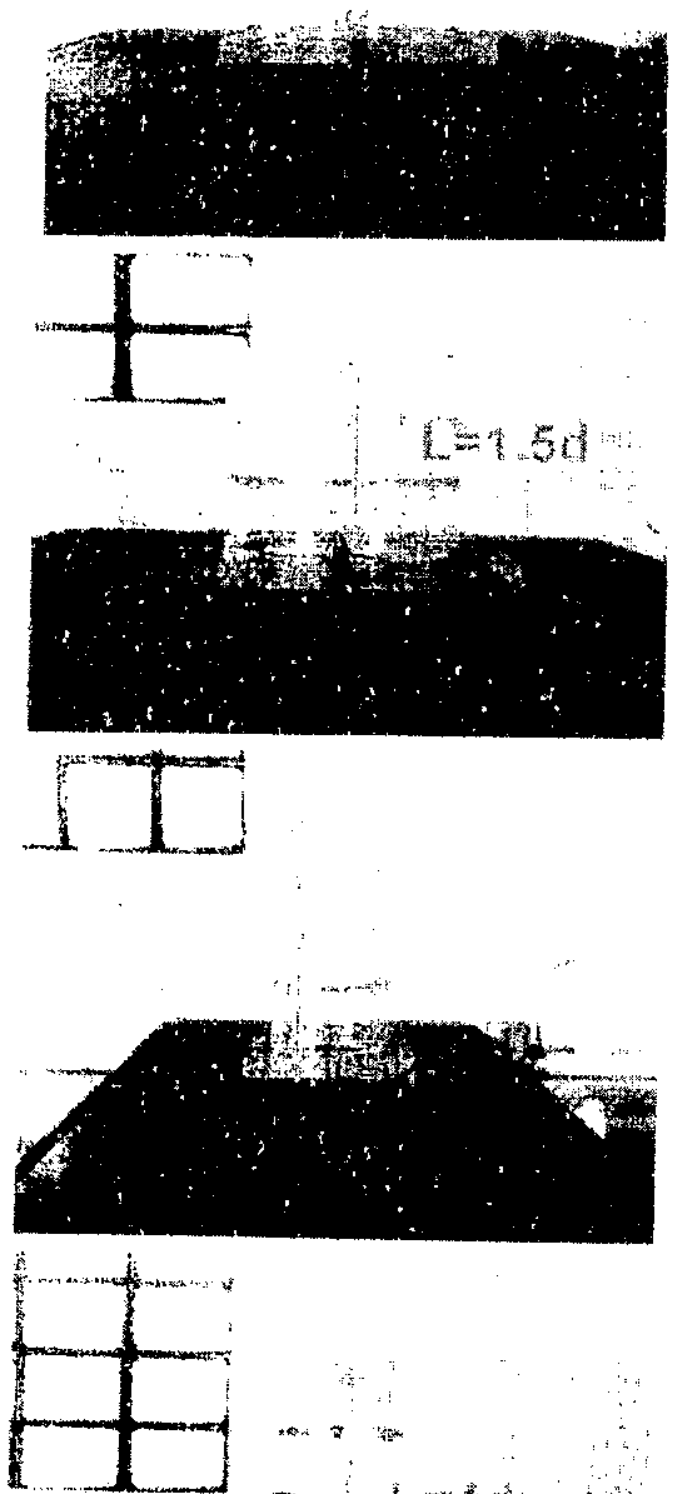

$*$ in -10

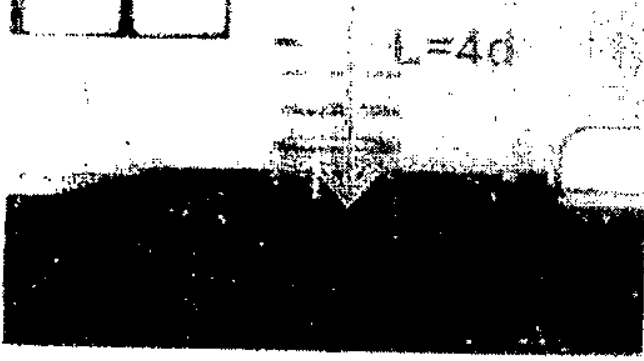

Photo (6) Different lengths of Transparent Mouthpieces
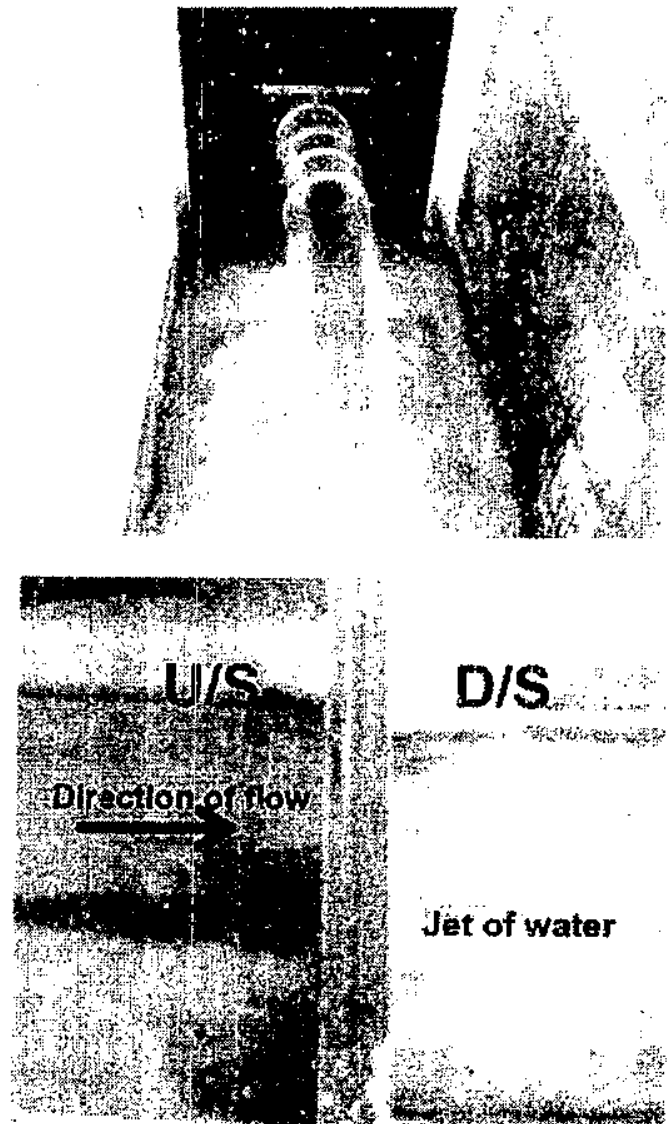

Photo (7) Monitoring the Flow at External Mouthpieces

\section{TEST PROGRAM AND EXECUTED MEASUREMENTS}

The test progzam was planned to check the different values of discharge coefficient at different operation conditions. Therefore, 126 runs were executed during which the length and position of the mouthpiece were varied. The tested lengths, with respect to the orifice diameter, were $0.5 \mathrm{~d}, 1 \mathrm{~d}, 1.5 \mathrm{~d}$, $2 \mathrm{~d}, 3 \mathrm{~d}, 4 \mathrm{~d}$ and $5 \mathrm{~d}$, while the tested positions of mouthpieces were fitting them either internally (opposite to the flow direction) or externally (along the flow direction). The discharge was varied from 5 to $13 \mathrm{l} / \mathrm{s}$ with an increment of $1 \mathrm{l} / \mathrm{s}$.

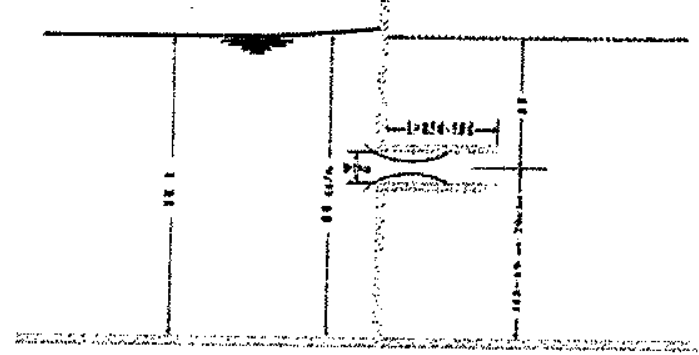

Figure 3. Mouthpiece with sharp entrance 


\section{TEST RESULTS}

The measurements were analyzed and graphically represented. A sample of the measurements is given in figures 4 to 11 .

These measurements were conducted at discharges that ranged between $51 / \mathrm{s}$ and $13 \mathrm{l} / \mathrm{s}$ with an increment of $1 \mathrm{l} / \mathrm{s}$ at a head of $(\mathrm{H})=\mathrm{Hu} / \mathrm{s}-20 \mathrm{~cm}$, external pipe orifice at a head of $(\mathrm{H})=\mathrm{Hu} / \mathrm{s}-15 \mathrm{~cm}$, internal pipe orifice at a head of $(\mathrm{H})=\mathrm{Hu} / \mathrm{s}-20 \mathrm{~cm}$, and internal pipe orifice at a head of $(H)=H u s-15$ $\mathrm{cm}$. The presented sample figures are at flowing discharges of $7 \mathrm{~V} / \mathrm{s}$ and $13 \mathrm{~V} / \mathrm{s}$ at different mouthpiece directions and positions of the mouthpiece.

As for the produced graphs, a sample is given on Figs. (4) to (11). They show the results of one test series that was investigated for the external pipe direction and internal pipe direction at a head of $(\mathrm{H})$ $=\mathrm{Hu} / \mathrm{s}-20 \mathrm{~cm}$ and $(\mathrm{H})=\mathrm{Hu} / \mathrm{s}-15 \mathrm{~cm}$ at flowing discharges $7 \mathrm{~V} / \mathrm{s}$ and $131 / \mathrm{s}$.
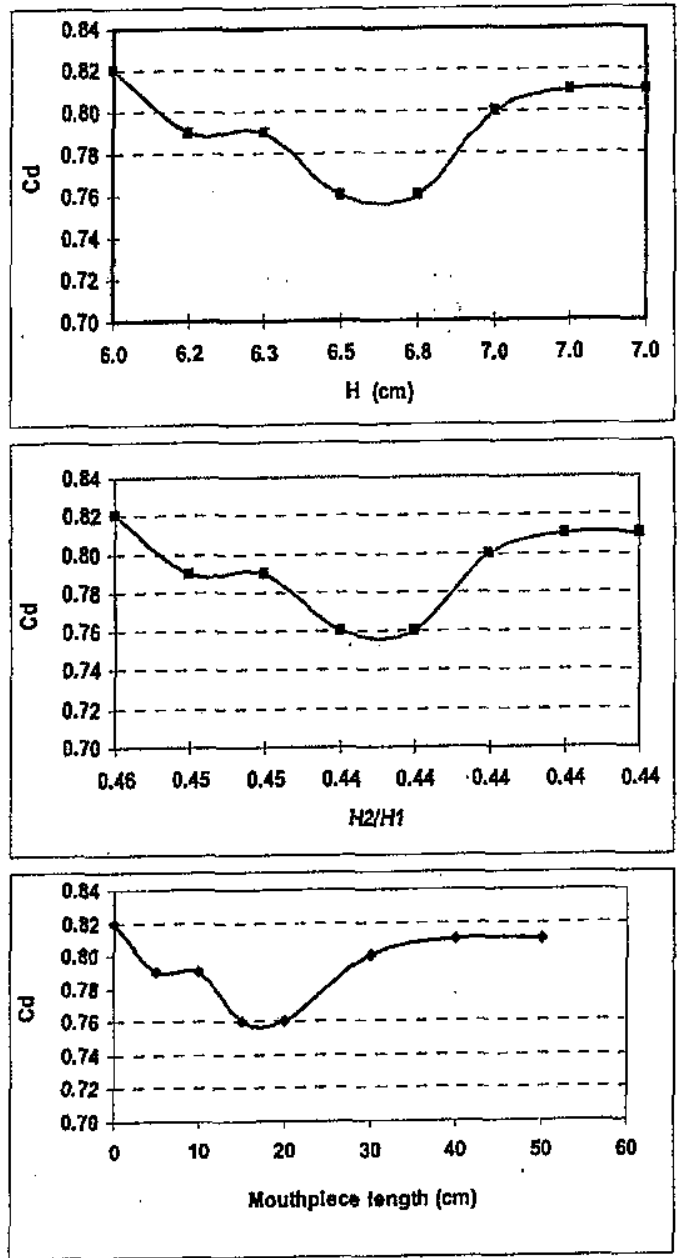

Figure 4. Effect of $\mathrm{H}, \mathrm{L} \& \mathrm{H}_{2} / \mathrm{H}_{1}$ on $\mathrm{C}_{\mathrm{d}}$ (External.Mouthpiece $-\mathrm{Q}=7 \mathrm{~L} / \mathrm{S}-\{\mathrm{H}=\mathrm{HU} / \mathrm{S}-20\}$
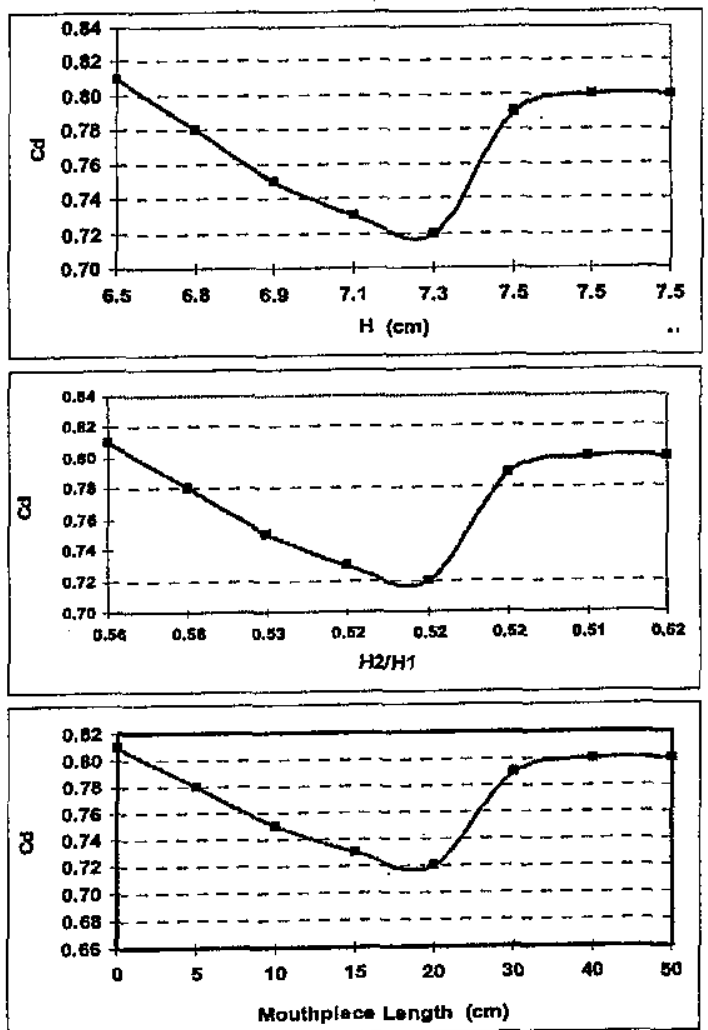

Figure 5. Effect of $\mathrm{H}, \mathrm{L} \& \mathrm{H}_{2} / \mathrm{H}_{1}$ on $\mathrm{C}_{\mathrm{d}}$ (External Mouthpiece $-\mathrm{Q}=7 \mathrm{~L} / \mathrm{S}-\{\mathrm{H}=\mathrm{HU} / \mathrm{S}-15\}$
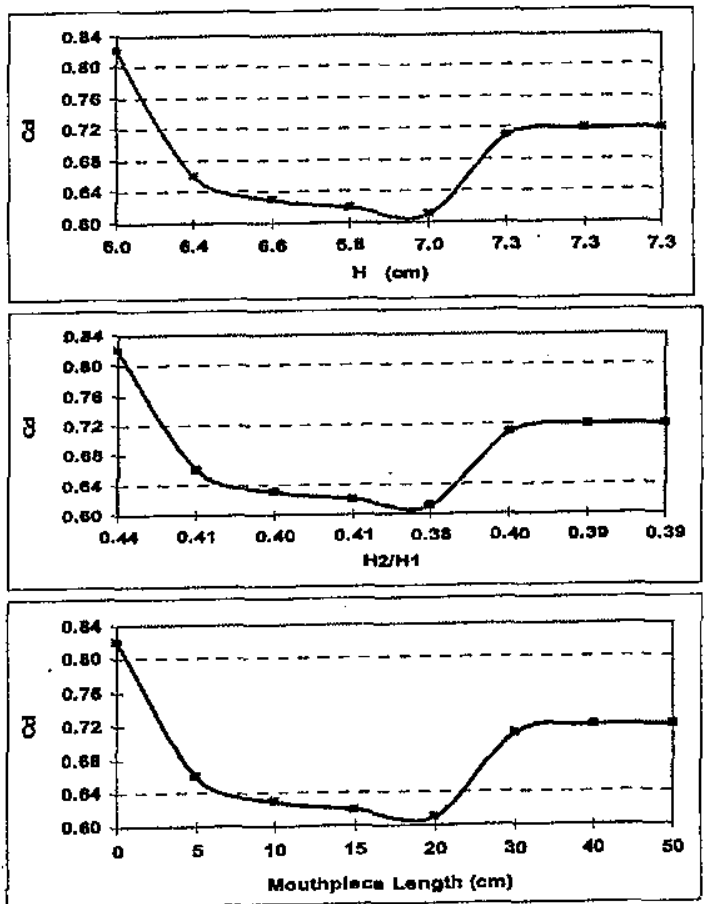

Figure 6. Effect of $\mathrm{H}, \mathrm{L} \& \mathrm{H}_{2} / \mathrm{H}_{1}$ on $\mathrm{C}_{\mathrm{d}}$ (Internal Mouthpiece $-\mathrm{Q}=7 \mathrm{~L} / \mathrm{S}-\{\mathrm{H}=\mathrm{HU} / \mathrm{S}-20\}$ 
Sayed E. A. Mahgoub, "Effect of Mouthpiece Length and Position on The Discharge Coefficient"
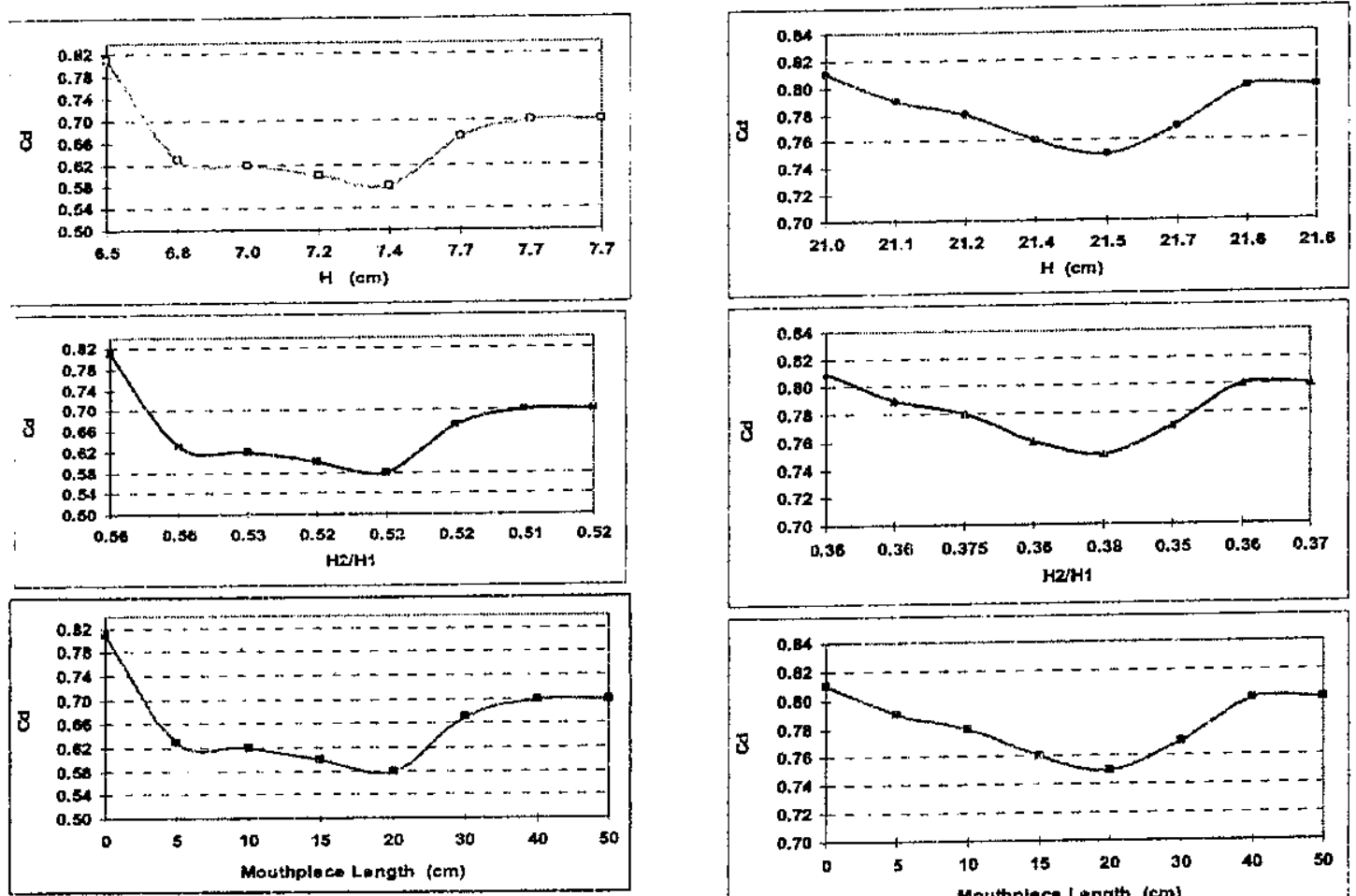

Figure 7. Effect of $\mathrm{H}, \mathrm{L} \& \mathrm{H}_{2} / \mathrm{H}_{1}$ on $\mathrm{C}_{\mathrm{d}}$ (Internal Mouthpiece $-\mathrm{Q}=7 \mathrm{~L} / \mathrm{S}-\{\mathrm{H}=\mathrm{HU} / \mathrm{S}-15\}$
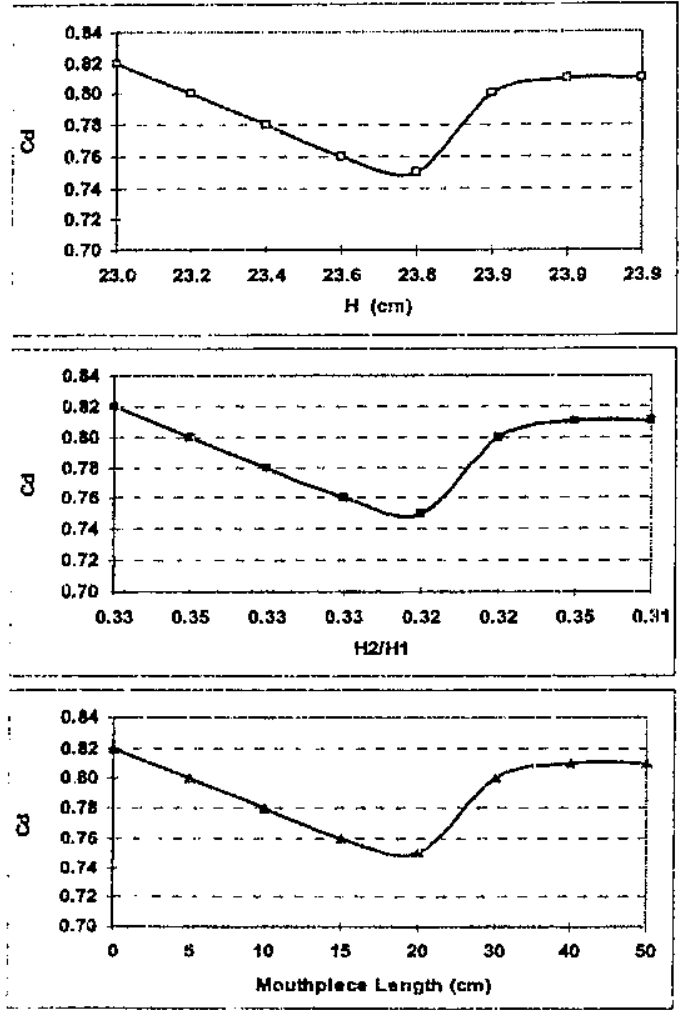

Figure \&. Effect of $\mathrm{H}, \mathrm{L} \& \mathrm{H}_{2} / \mathrm{H}_{1}$ on $\mathrm{C}_{\mathrm{d}}$ (Extemal Mouthpiece $-\mathrm{Q}=13 \mathrm{~L} / \mathrm{S}-\{\mathrm{H}=\mathrm{HU} / \mathrm{S}-20\}$

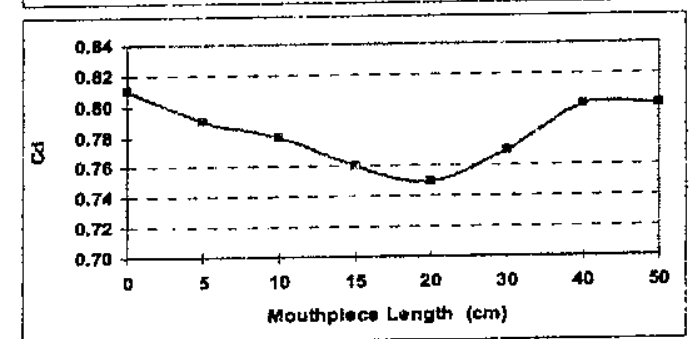

Figure 9. Effect of $\mathrm{H}, \mathrm{L} \& \mathrm{H}_{2} / \mathrm{H}_{1}$ on $\mathrm{C}_{\mathrm{d}}$ (External Mouthpiece $-\mathrm{Q}=3 \mathrm{~L} / \mathrm{S}-\{\mathrm{H}=\mathrm{HU} / \mathrm{S}-15\}$
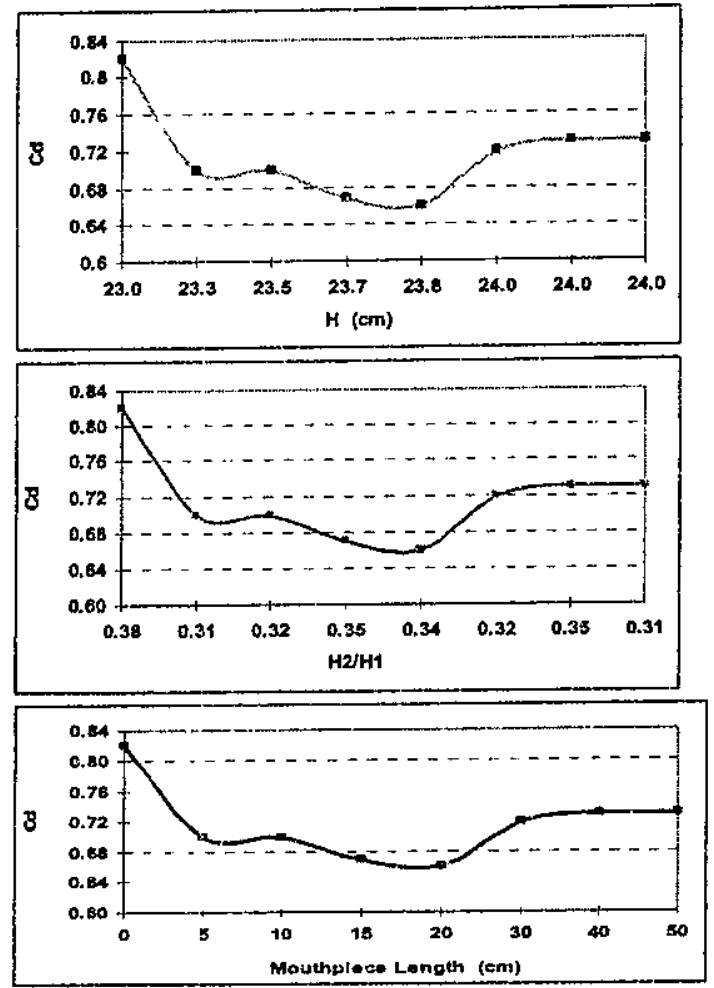

Figure 10. Effect of $\mathrm{H}, \mathrm{L} \& \mathrm{H}_{2} / \mathrm{H}_{1}$ on $\mathrm{C}_{\mathrm{d}}$ (Internal Mouthpiece-Q=13L/S- $\{\mathrm{H}=\mathrm{HU} / \mathrm{S}-20\}$ 
Sayed E. A. Mahgoub, "Effect of Mouthpiece Length and Position on The Discharge Coefficient"
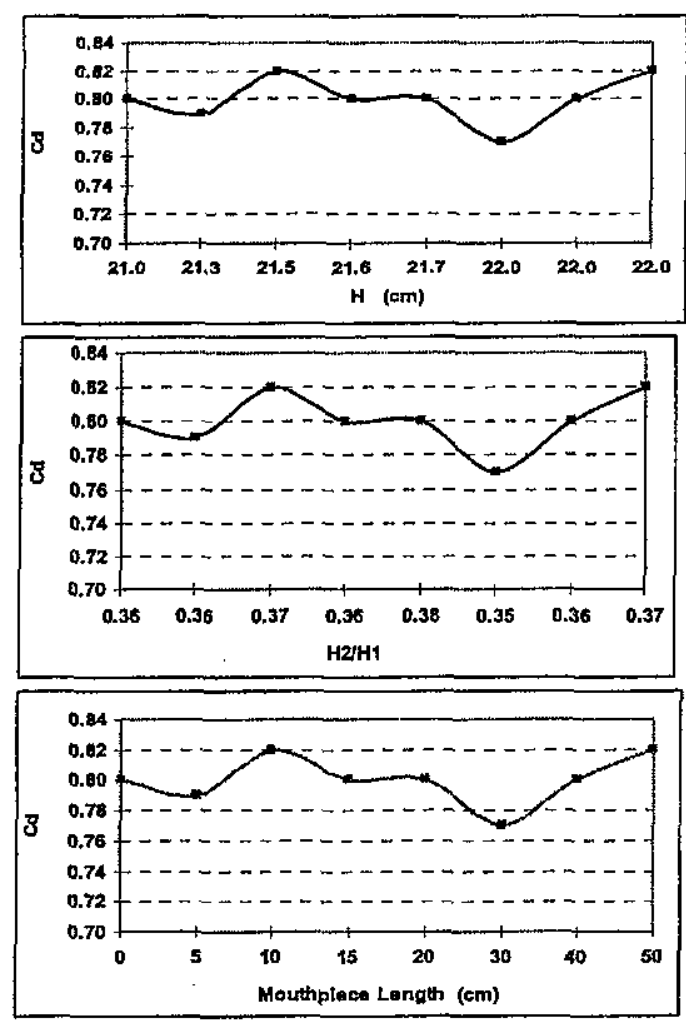

Figure 11. Effect of $\mathrm{H}, \mathrm{L} \& \mathrm{H}_{2} / \mathrm{H}_{1}$ on $\mathrm{C}_{\mathrm{d}}$ (Internal Mouthpiece- $\mathrm{Q}=13 \mathrm{~L} / \mathrm{S}-\{\mathrm{H}=\mathrm{HU} / \mathrm{S}-15\}$

\section{CONCLUSIONS}

From the experimental work, the following was concluded:

- As the length of the moutbpiece increases, the discharge coefficient $\left(\mathrm{C}_{\mathrm{d}}\right)$ decreases till a limit after which it becomes constant.

- Using internal mouthpieces increases the losses in case of using external mouthpieces due to the fact that the separation increases.

- Using internal mouthpieces, the discharge coefficient $\left(C_{d}\right)$ is less with about $20 \%$.

- Increasing discharge leads to decreasing $\mathrm{H}_{2} / \mathrm{H}_{1}$.

- Lowering the orifices under free surface induces higher losses.

- Lowering the orifices under free surface results in decreasing $\mathrm{Hu} / \mathrm{s}$ and increasing $\mathrm{H}_{2} / \mathrm{H}_{1}$.

- $\mathrm{HU} / \mathrm{s} / \mathrm{HD} / \mathrm{s}$ are affected by the discharge, the length, the height and direction of the mouthpiece.

\section{BIBLIOGRAPHY}

[1] El-Mongy, A., El-Bisy, M. and El-Saeed ,G., " Fluid Mechanics", Ain Shams University, 2005.

[2] Henderson, "Open Channel Flow", Macmillan Publishing Co., Inc., New York, 1966.

[3] Richard H. French, "Open Channel Hydraulics", Mc Graw-Hill, Inc., 1985.

[4] Sobeh M. M., "Hydraulics and Elementary Fluid Mechanics", Menoufia University, 2006. 